\title{
Política de comunicação científica em rede: repositórios institucionais como dispersão
}

Viviane Toraci Alonso de Andrade vivianetoraci@hotmail.com

Universidade Federal de Pernambuco

Resumo: A atual política de comunicação científica em rede valoriza os investimentos individuais, seja de pesquisadores ou de instituições. Incentiva o acesso livre através da autopublicação e da constituição de repositórios institucionais. Defendemos nesse artigo uma outra forma de organização da informação científica em rede, demonstrando que os repositórios institucionais são dispersivos. Nossa proposta é concentrar os fluxos informacionais numa Plataforma de Conhecimento.

Palavras-chave: acesso livre; plataforma de conhecimento; colaboração.

Abstract: The current policy of scientific communication network values the individual investments, whether researchers or institutions. Encourages open access by self-publishing and the creation of institutional repositories. We defend that article another form of organization of scientific information network, demonstrating that institutional repositories are dispersive. Our proposal is to concentrate information flows in a Knowledge Platform.

Keywords: open access; knowledge platform; collaboration.

\section{INTRODUÇÃO}

Na década de 90, após a queda do Muro de Berlim e com a ascensão do neoliberalismo, cresce a responsabilização do indivíduo, levando ao desmantelamento do "Estado Providência" e ao crescimento da concepção de indivíduo autônomo, responsável e reflexivo. No mesmo período, cresce o número de pontos conectados à rede mundial de computadores com a abertura para exploração comercial do provimento de acesso. Não por acaso, a união entre um indivíduo autônomo e uma rede de comunicação com vias de mão dupla (fusão entre emissores e receptores) faz emergir o movimento de autopublicação na rede e acesso livre, com sites amadores, blogs e, em 1999, o manifesto do Open Arquives Initiative (OAI). Partindo da sugestão de padrões de interoperabilidade, o movimento se desenvolve defendendo a comunicação ampla e irrestrita dos resultados de pesquisas financiadas com recursos públicos. Em site oficial (www.openarchives.org) destaca que seus princípios se baseiam no livre acesso e nos movimentos de repositórios institucionais. A filosofia do livre acesso conquistou a comunidade acadêmica mundial, levando ao 
desenvolvimento de diversos periódicos online com livre acesso e repositórios institucionais compostos por pré-prints e pós-prints de artigos científicos, teses e dissertações na íntegra, documentos diversos da produção técnica e científica das instituições de ensino e pesquisa.

Contudo, a explosão da disponibilização da informação científica em rede nos coloca agora o problema da dispersão: estamos em meio a um labirinto de periódicos e repositórios online, muitas vezes com informações redundantes, que exigem grande esforço descentralizado nas instituições para sua manutenção e dos pesquisadores para sua utilização como fontes de pesquisa. A responsabilização dos indivíduos - sejam os pesquisadores que autopublicam suas produções, seja cada instituição de ensino e pesquisa que mantém seu próprio repositório - significou a dispersão dos investimentos financeiros, em pessoal e em equipamentos. Podemos comparar tal dispersão ao investimento individual na compra de um automóvel em detrimento ao investimento público na disponibilização de uma solução coletiva, como em trens, analogia realizada por Tony Judt (2011). Podemos imaginar uma solução coletiva capaz de concentrar os documentos produzidos pelos cientistas brasileiros sob financiamento público numa única plataforma, assim como temos em funcionamento a Plataforma Lattes para os currículos científicos. Ao invés de pesquisarmos em cada site de cada instituição o nome e o currículo de um pesquisador de interesse, ou os pesquisadores que compõem uma área, temos como solução informacional a Plataforma Lattes, alimentada por cada pesquisador interessado em manter as informações atualizadas de modo a permitir progressões na carreira e financiamentos para pesquisa. Percebe-se a ação do Governo apresentando condições ao indivíduo para o bem da coletividade. Será essa discussão entre o papel do Governo na dispersão/concentração de fluxos que trataremos nesse artigo.

\section{ACESSO LIVRE E REPOSITÓRIOS INSTITUCIONAIS}

As iniciativas de disponibilização de informações científicas na rede mundial de computadores cresceram a partir de 1990, quando algumas revistas científicas passam a disponibilizar seu conteúdo em formato eletrônico, distribuindo para bibliotecas CD ROMs como também versões online. Para as bibliotecas, era uma boa solução para seus problemas de espaço para armazenamento dos volumes impressos, bem como um caminho para barateamento na aquisição dos periódicos científicos. Em 1991, a Universidade de Los Alamos (EUA) cria o repositório institucional ArXiv, posicionando-se na vanguarda do pensamento de acesso livre ao conhecimento produzido na academia. Em 1993, vários títulos científicos publicam na Internet réplicas de suas versões impressas, utilizando principalmente arquivos em PDF, mas ainda com pesquisadores-autores cautelosos em utilizar os veículos 
exclusivamente online. Em 1995, a Sociedade Americana de Astronomia, a Editora da Universidade de Chicago e a NASA criam o NASA Astrophysics Data System:

Permite a busca em metadados, resumos e no texto completo, além de oferecer acesso ao texto integral de toda a coleção, proporcionar links e referência cruzada entre as citações de todos os artigos da coleção. Além do mais, emite relatórios estatísticos de citação, acesso e outros. (ARELLANO; FERREIRA; CAREGNATO, 2005, p. 197-199)

Finalmente, em 1999, é criado na Convenção de Santa Fé (EUA) o manifesto do Open Arquives Iniciative, trazendo um novo paradigma para a comunicação científica. A Figura 1 demonstra essa rápida evolução do uso das tecnologias eletrônicas na comunicação científica.

Figura 1 - Tecnologias eletrônicas na comunicação científica

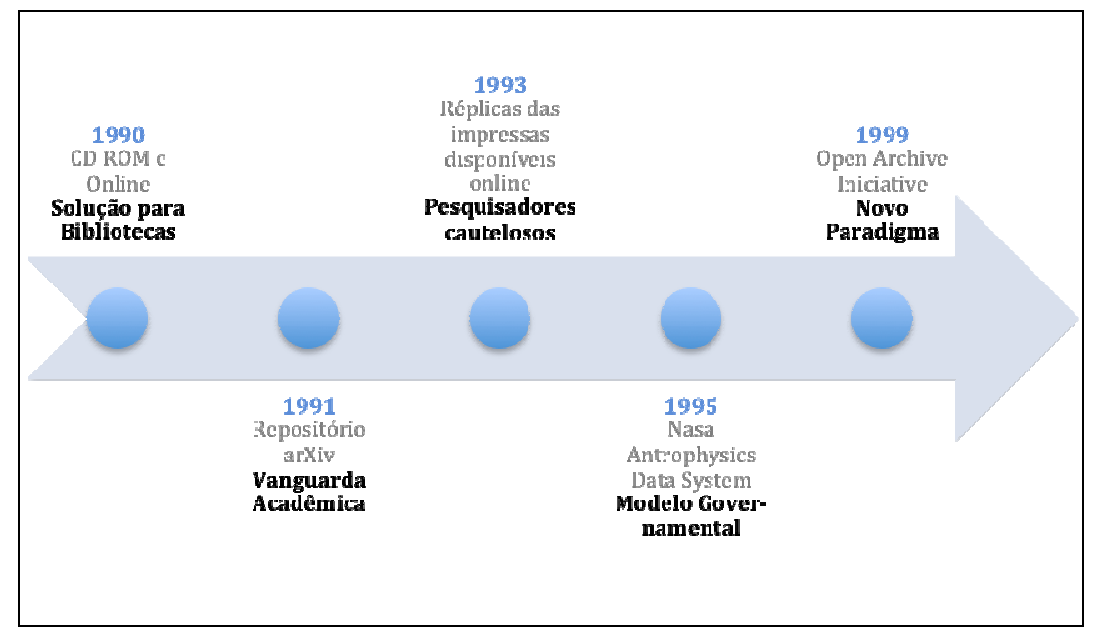

Fonte: Formulação da autora.

Os movimentos de Acesso Livre nasceram como uma reação dos pesquisadores à industrialização das revistas científicas, que ao compor os catálogos de editoras comerciais são vendidas com altos preços de assinaturas; e também como fruto de uma crescente conscientização do impacto positivo da disponibilização de conteúdos científicos de forma livre. O foco dos movimentos é a comunicação ampla e irrestrita dos resultados de pesquisas financiadas com recursos públicos. O principal expoente desse pensamento é o Open Archives Iniciative (OAI), que tem como missão desenvolver e promover padrões de interoperabilidade que buscam facilitar a comunicação eficiente de conteúdo. OAl baseia seus princípios no livre acesso e nos movimentos de repositórios institucionais. Suas maiores contribuições estão no desenvolvimento e suporte de softwares e padrões de linguagem capazes de viabilizar a interoperabilidade entre os sistemas, como o The Open Archive Iniciative Protocol for Metadata Harvesting (OAI-PMH) e o Open Archives Iniciative Object Reuse and Exchange (OAIORE). 
O novo paradigma do Acesso Livre à Informação baseia-se nos termos da Declaração de Budapeste (BOAI - Budapest Open Access Initiative - 2002) e da Declaração de Berlim sobre o Acesso Livre ao Conhecimento nas Ciências e Humanidades (Berlin Declaration on Open Access to Knowledge in the Sciences and Humanities - 2003). Em Budapeste foram organizados e documentados os conceitos base do movimento, como a seguinte definição para Acesso Livre:

\begin{abstract}
"Acesso livre" à literatura científica revisada por pares significa a disponibilidade livre na Internet, permitindo a qualquer usuário ler, fazer download, copiar, distribuir, imprimir, pesquisar ou referenciar o texto integral desses artigos, recolhe-los para indexação, introduzi-los como dados em software, ou usá-los para outro qualquer fim legal, sem barreiras financeiras, legais ou técnicas que não sejam inseparáveis ao próprio acesso a uma conexão à Internet. As únicas restrições de reprodução ou distribuição e o único papel para o direito autoral neste domínio é dar aos autores o controle sobre a integridade do seu trabalho e o direito de ser devidamente reconhecido e citado. (Budapest Open Access Initiative, 2002, tradução)
\end{abstract}

Como caminhos para viabilizar a disponibilização dos conteúdos em acesso livre, foram sugeridas duas vias: a Via Verde, disponibilizando por autoarquivamento os conteúdos em repositórios de acesso livre; e a Via Dourada, como edição em acesso livre, sugerindo a disponibilização de revistas científicas online em acesso livre. No ano seguinte, em Berlim, foram estabelecidos os tipos e condições dos documentos a integrarem os repositórios ou revistas em acesso livre:

I. Contribuições em acesso livre incluem resultados de pesquisas científicas originais, dados não processados, metadados, fontes originais, representações digitais de materiais pictóricos, gráficos e material acadêmico multimídia.

II. As contribuições em acesso livre devem satisfazer duas condições:

1. o(s) autor(es) e o(s) detentor(es) dos direitos de tais contribuições concede(m) a todos os usuários:

a. direito gratuito, irrevogável e irrestrito de acessá-las;

b. licença para copiá-las, usá-las, distribuí-las, transmiti-las e exibi-las publicamente;

c. licença para realizar e distribuir obras derivadas, em qualquer suporte digital para qualquer propósito responsável, em obediência à correta atribuição da autoria (as regras da comunidade continuarão a fornecer mecanismos para impor a atribuição e uso responsável dos trabalhos publicados, como acontece no presente) e com a garantia de fazer cópias; 
2. Uma versão completa da obra e todos os materiais suplementares, incluindo uma cópia da licença, como acima definida, é depositada e, portanto, publicada em um formato eletrônico normalizado e apropriado em pelo menos um repositório que utilize normas técnicas adequadas (como as definições estabelecidas pelo modelo Open Archives) e que seja mantido por uma instituição acadêmica, sociedade científica, organismo governamental, ou outra organização estabelecida que pretenda promover o acesso livre, a distribuição irrestrita, a interoperabilidade e o arquivamento a longo prazo.

Ambas as vias consideram as práticas estabelecidas pela comunidade científica. Na Via Dourada, os periódicos científicos online mantêm os gêneros tradicionalmente publicados nas revistas científicas, como artigos, comunicações, entrevistas, resenhas. A política editorial baseada na revisão pelos pares permanece, tendo como diferencial apenas sua disponibilização na rede para acesso livre. Percebe-se, inclusive, a continuidade da estética do impresso, com os textos em formato PDF.

A Via Verde incentiva a criação dos repositórios institucionais. Como citado anteriormente, este espaço prevê maior amplitude de gêneros, inclusive os multimídias. Por questões culturais da comunidade científica, tem-se ainda como principal fonte de legitimidade da ciência a revisão por pares, levando um maior número de cientistas a publicarem nos repositórios institucionais seus pós-prints (artigos publicados em revistas científicas e também disponibilizados no repositório institucional para livre acesso) em detrimento aos manuscritos. Entretanto, é colocada esta nova possibilidade: a publicação de pré-prints. Tratam-se dos textos ainda não revisados por pares, ou seja, ainda não publicados em nenhum espaço oficial. Ao aceitar ler um pré-print, o leitor sabe que está acessando um conteúdo novo, mas não necessariamente aprovado pela comunidade científica. Como a publicação de um pré-print é datada pelo repositório, sua principal função é marcar autoria, como também receber contribuições para uma futura publicação.

Brody e Harnad (apud LEITE, 2009) apresentam como se dá o acesso e qual o impacto do autoarquivamento, ou seja, a disponibilização de pré-prints em repositórios institucionais (Figura 2). O cientista, com um manuscrito produzido, o publica como pré-print no repositório de sua instituição. Ele pode optar por aguardar os comentários espontâneos dos pares ou, paralelamente, já submeter o original a um processo de avaliação por pares para publicação num periódico. A partir da publicação do pré-print, pode-se alcançar um ciclo de impacto grande e rápido, pois o acesso é maximizado e acelerado. Enquanto isso, o texto é avaliado por pares, publicado por um periódico, disponibilizado em versão impressa e/ou online oficial da revista científica, que ao manter seu conteúdo fechado para assinantes, provê um acesso lento 
e limitado. Somente depois ele poderá ser publicado no repositório institucional como pósprint.

Figura 2 - Acesso e impacto da pesquisa maximizados através do autoarquivamento

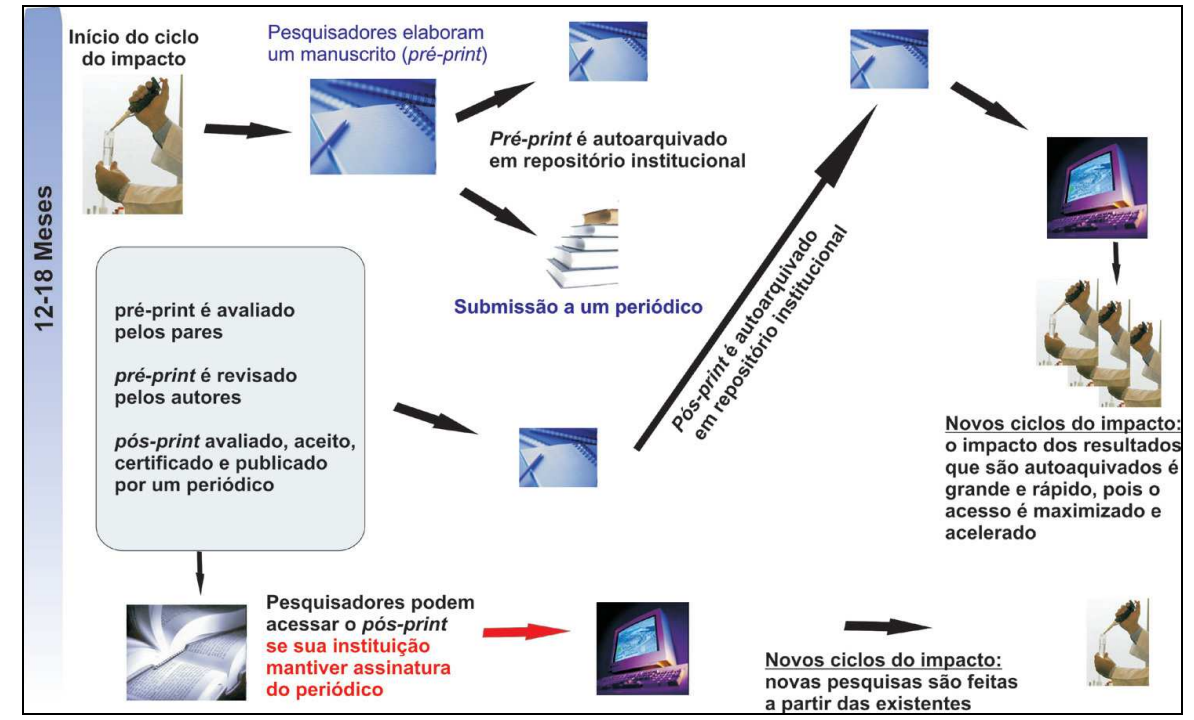

Fonte: Brody e Harnad (apud LEITE, 2009).

Estamos tratando aqui de textos, em sua maioria, produzidos e distribuídos por vias eletrônicas digitais em rede. Temos, assim, um crescimento importante da leitura de conteúdo científico em telas. Darnton observa o crescimento da legitimidade dos textos em telas, ainda os relacionando ao formato do livro:

Uma população cada vez maior de nativos digitais acha natural ler em máquinas. Muitos dos leitores mais velhos se familiarizaram com o ato de clicar em textos e seguir raciocínios através de links em vez de virar páginas em ordem consecutiva. Embora o códice impresso ainda domine o mercado, não inspira mais autoridade como única forma possível do livro (DARNTON, 2010, p. 104).

Temos uma maior adesão da comunidade científica aos princípios do Acesso Livre quando da publicação de artigos, os quais desde seu nascimento, não geram benefícios de copyright para seus autores. Quando falamos de livros, percebemos a preocupação com os direitos autorais, trazendo à tona o Creative Commons. Ele surgiu da necessidade de por um lado criar um mecanismo jurídico que possibilitasse aos autores licenciar suas obras de maneira simples sem ter que recorrer aos altos preços das consultorias dos advogados e por outro formar um conjunto de obras de livre acesso aos indivíduos. É um projeto que tem por objetivo disponibilizar licenças de uso de obras padronizadas, que permitam ao público em geral usar, copiar, modificar e distribuir estes conteúdos ao mesmo tempo em que assegura os direitos dos autores, os quais registram no site da instituição suas obras de forma voluntária. 
Ao registrá-la, devem indicar os usos permitidos, sendo previstas as seguintes modalidades, as quais são identificadas pelos ícones apresentados no Quadro 1.

Quadro 1- Ícones Creative Commons (CC)

\section{cC}

\begin{tabular}{|l|l|}
\hline & $\begin{array}{l}\text { Atribuição. Você permite que outras pessoas copiem, distribuam e executem sua obra, } \\
\text { protegida por direitos autorais - e as obras derivadas criadas a partir dela - mas somente } \\
\text { se for dado crédito da maneira que você estabeleceu. }\end{array}$ \\
& $\begin{array}{l}\text { Não a obras derivadas. Você permite que outras pessoas copiem, distribuam e executem } \\
\text { somente cópias exatas da sua obra, mas não obras derivadas. }\end{array}$ \\
\hline & \begin{tabular}{l} 
Compartilhamento pela mesma licença. Você pode permitir que outras pessoas \\
distribuam obras derivadas somente sob uma licença idêntica à licença que rege sua obra. \\
\hline
\end{tabular} \\
\hline
\end{tabular}

Fonte: Creative Commons. Disponível em: $\langle$ http://www.creativecommons.org.br>.

Acesso em: 2 maio 2012.

Os reflexos dessas iniciativas podem ser verificados nas práticas de publicação dos cientistas brasileiros. Em sua maioria, os programas de pós-graduação do país mantêm suas revistas científicas eletrônicas em acesso livre, atitude incentiva pelo Ministério da Ciência, Tecnologia e Inovação (MCTI) com a disponibilização do software de gestão de revistas eletrônicas - o Sistema Eletrônico de Editoração de Revistas (SEER), traduzido e customizado pelo Instituto Brasileiro de Informação em Ciência e Tecnologia (Ibict) a partir do software Open Journal Systems (OJS) (http://pkp.sfu.ca/ojs), do Public Knowledge Project (PKP), mantido pela British Columbia University (Canadá). Em notícia veiculada no site do Ibict em 2 de maio de 2012, comemorava-se o registro de 100 portais de periódicos científicos no sistema, sendo 29 de universidades públicas e 71 de universidades particulares de todo o país. Também, encontramos muitas publicações científicas sob Creative Commons circulando na Internet.

As reinvidicações e iniciativas estão assentadas nas formas de armazenamento e acesso aos conteúdos. O foco até então foi o da livre circulação, a qual confere maior visibilidade para a ciência e seus produtores, ampliando assim os benefícios gerados pelo conhecimento científico. O crescimento exponencial dos conteúdos científicos em redes digitais nos leva, então, a outro problema: o excesso de informação. 
Os membros do público, bem como os pesquisadores, sentem-se cada vez mais assoberbados de informação. A não ser que a recuperação da informação seja altamente personalizada (isto é, no nível e conteúdo certos, e disponível imediatamente), os usuários não terão como se aprofundar. A pergunta formulada por T. S. Eliot e tantas vezes citada “Onde está o conhecimento que perdemos na informação?" -, talvez seja, para todos os usuários da informação científica, uma das indagações mais importantes a serem dirimidas no século XXI (MEADOWS, 1999, p.244).

Foi assim que Meadows, ao final do século XX, definiu o cenário da comunicação científica, que em relação ao volume encontrado atualmente, ainda engatinhava na disponibilização de conteúdos em redes digitais. Ele foi muito feliz ao resgatar o desafio lançado por T. S. Eliot, afinal a informação pode estar disponível, mas é preciso saber como transformá-la em conhecimento. Ele pode ser fruto do esforço pessoal de cientistas geniais, mas provavelmente perceberemos uma maior representatividade do conhecimento gerado a partir das colaborações, da união de cientistas de todo o mundo empenhados em desenvolver o conhecimento de forma conjunta e com o crescimento global da comunicação científica em rede. Como expôs Mascarenhas e Silva (2008):

Concordamos totalmente com a ideia de se sociabilizar integralmente o conhecimento científico, mas chamamos novamente a atenção para o fato de que disponibilizar e acessar documentos eletrônicos depende de soluções tecnológicas, enquanto que o fluxo e a comunicação da informação exigem outras ações que envolvem processos de tratamento e organização da informação (MASCARENHAS E SILVA, 2008, p. 72).

É exatamente nesse ponto que queremos iniciar nossa discussão: não basta disponibilizar e acessar de forma dispersa. É preciso pensar processos de tratamento e organização da informação que melhorem o fluxo da comunicação científica em rede.

\section{REPOSITÓRIOS INSTITUCIONAIS COMO DISPERSÃO}

Defenderemos que o acesso livre a informação científica é benéfica para a comunidade acadêmica e para os cidadãos. Entretanto, criticamos o atual esforço dispersivo da criação dos repositórios institucionais, propondo então uma outra forma de publicação na rede.

Os repositórios institucionais representam o poder individual de ação, ou seja, cada pesquisador e cada instituição de pesquisa teriam a liberdade de compor sua política de publicação em acesso livre, incentivando a disponibilização do conhecimento produzido sob financiamento público. Entretanto, a nossa concepção de liberdade está muito atrelada ao individualismo. Vamos trabalhar com a ideia de fluxos fazendo uma analogia entre o trânsito nas vias públicas e o trânsito nas vias informacionais. 
O modelo brasileiro de organização do trânsito nas vias públicas foi concebido de modo a privilegiar o uso do veículo individual, ou seja, o carro. Temos muitas ruas, avenidas, viadutos. Mas poucas linhas de trem em funcionamento, metrôs, ônibus, ciclovias ou até mesmo calçadas. O carro tem prioridade, seja na construção de rodovias, seja na redução de impostos para incentivar a indústria automobilística. Judt (2011) utiliza a comparação entre sociedades que investiram em soluções individuais de transporte e as que preferiram as soluções coletivas como símbolos de modelos de pensamento do Estado. Aquelas que investiram em trens mantiveram políticas de grandes investimentos públicos em prol dos interesses coletivos, enquanto as que investiram em rodovias, algumas vezes até abandonando as malhas ferroviárias existentes, promoveram o esvaziamento das políticas para o bem comum, privilegiando a proteção do mercado privado.

Se não conseguirmos perceber o valor de investir recursos coletivos nos trens, não será apenas por termos todos nos mudado para condomínios fechados, sem necessidade de outro meio de transporte além do automóvel para nos conduzir de um lugar a outro. Será porque nos transformamos em indivíduos fechados que não sabem como compartilhar o espaço comum para benefício mútuo (JUDT, 2011, p. 196).

Ao pensarmos na organização das vias informacionais, podemos considerar repositórios institucionais como carros. É bom ter um carro, todo mundo quer um. Ele nos dá a liberdade de irmos aonde quisermos, na hora que quisermos, utilizando o roteiro que preferirmos. E é cada um fazendo o que é melhor para si que atingimos o estágio atual de caos urbano, com cidades paradas no trânsito de milhares de carros com um passageiro, exigindo do governo uma solução (que permita que eu continue andando com o meu carro). Quando o carro surgiu, teve início uma revolução. Mas hoje percebemos suas consequências nefastas. Quando os repositórios institucionais nasceram, foram sinônimo de liberdade. Mas agora vemos o outro lado.

Para uma instituição de pesquisa criar e manter seu repositório institucional é preciso investimentos contínuos, passando pelas fases descritas por Leite (Figura 3) de planejamento, implementação e formas de assegurar a participação da comunidade. É preciso mobilizar uma equipe, que irá definir a política de publicação da instituição, bem como manter a comunidade incentivada a participar do repositório, de modo que cumpra sua função de visibilidade.

Não é fácil cumprir a burocracia das fases de planejamento e implementação, bem como depois convencer a comunidade da validade da ação. Por isso a comparação com o investimento em carros: são esforços descentralizados que trazem pouco benefício para o bem comum. Não estamos com isso negando os benefícios do acesso livre à comunicação científica. Mas o formato valorizado atualmente de repositórios institucionais. 
Figura 3 - Fases da construção de repositórios institucionais de acesso aberto

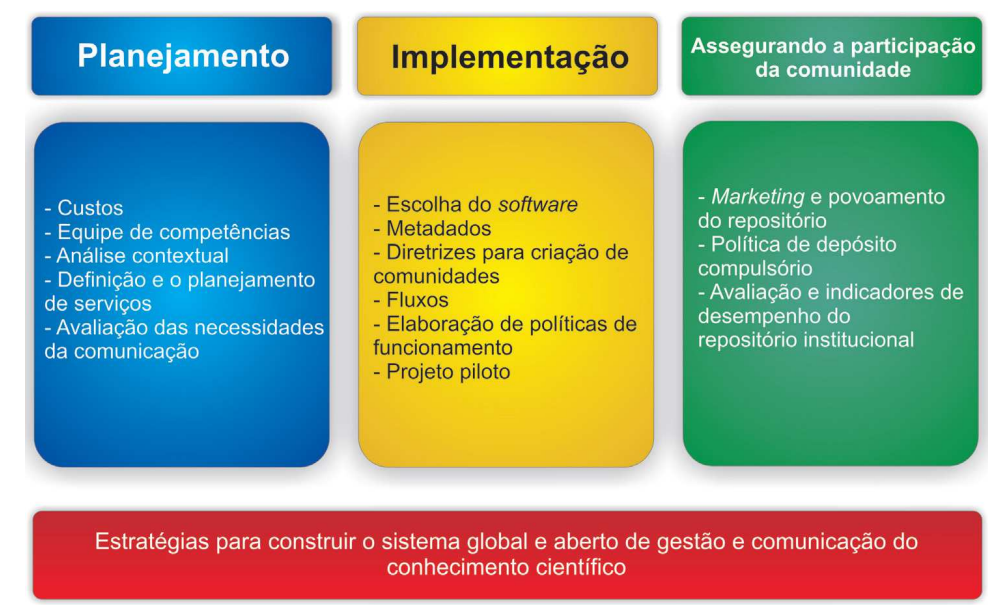

Fonte: Leite (2009).

Temos dois exemplos de esforços do Governo Federal brasileiro para implementação de repositórios institucionais que não alcançaram os resultados esperados: o Projeto de Lei 1120/2007 do Deputado Rodrigo Rollemberg que trata do processo de disseminação da produção técnico-científica do Brasil e dá outras providências e os editais para apoio a projetos de implantação de repositórios institucionais nas instituições públicas federais, estaduais e municipais de ensino e pesquisa capitaneados pela Fundação de Ciência, Aplicações e Tecnologia Espaciais (Funcate), em convênio com a Financiadora de Estudos e Projetos (Finep), e com o Instituto Brasileiro de Informação em Ciência e Tecnologia (Ibict) como executor.

O PL 1120/2007 foi arquivado em janeiro de 2011 após a apreciação de diversas comissões parlamentares. $O$ projeto tinha a intenção de determinar que as instituições de educação superior de caráter público e as unidades de pesquisa constituíssem repositórios institucionais de acesso livre na rede mundial de computadores à sua produção técnicocientífica. Nesses repositórios, deveria ser obrigatoriamente depositado:

[...] o inteiro teor da produção técnico-científica conclusiva dos estudantes aprovados em cursos de mestrado, doutorado, pós-doutorado ou similar, assim como da produção técnico-científica, resultado de pesquisas científicas realizadas por seus professores, pesquisadores e colaboradores, apoiados com recursos públicos (PL 1120/2007).

Com isso, tenta obrigar as instituições a organizarem seus repositórios institucionais o que não desobrigaria o Governo Federal dos investimentos necessários - e tornaria a fase de "participação da comunidade" algo compulsório. Sob a autoria da "comunidade científica brasileira" foi disponibilizada a Petição online para aprovação desse Projeto de Lei, fazendo crescer no Brasil a discussão sobre o acesso livre a produção científica sob financiamento público. Mesmo sem a aprovação da Lei, foi iniciado através dos editais para apoio aos 
projetos de implantação de repositórios institucionais o esforço para entregar as instituições públicas com programas de pós-graduação reconhecidos pelo Ministério da Educação (MEC) um kit tecnológico, em regime de comodato, composto por um servidor pré-formatado e configurado com o sistema operacional baseado na plataforma Unix/Linux, com os softwares Apache, MySQL, Dspace e SEER.

O projeto do então Deputado Rodrigo Rollemberg, agora Senador, foi substituído por um Projeto de Lei do Senado (PLS 387/2011), dispondo sobre o processo de registro e disseminação da produção técnico-científica pelas instituições de educação superior, bem como as unidades de pesquisa no Brasil e outras providências. Podemos ponderar que nossos legisladores federais não precisariam ocupar-se durante tanto tempo - desde a abertura do PL em 2007 até o presente momento - com uma questão que poderia, caso necessário, ser instituída por uma portaria ministerial. Quanto aos editais para entrega dos kits, é aqui principalmente que questionamos a dispersão dos investimentos ao entregar a responsabilidade às instituições isoladamente. Na prática, percebemos dois fortes argumentos que demonstram tal dispersão:

a) Mesmo equipando as instituições públicas de pesquisa com hardwares e softwares, ainda assim é preciso manter os sistemas funcionando. Para isso, é preciso equipe especializada, a qual deveria ser contratada via concurso. Como os concursos demoram, ou muitas vezes não são autorizados pelo Governo Federal, a equipe acaba sendo formada por profissionais da casa, que acumulam funções, e ainda tentam se adaptar às novas demandas técnicas. Com isso, em pouco tempo, o repositório institucional apresenta problemas técnicos, o público usuário o abandona, e consequentemente, também os pesquisadores não valorizam a disponibilização de seus conteúdos nesses bancos de dados.

b) Quando dizemos que os repositórios institucionais podem gerar maior visibilidade para a produção científica da instituição, e de todo o país, realizamos uma generalização que não condiz com a realidade da maioria das instituições de pesquisa do Brasil. Geramos maior visibilidade para quem já tem visibilidade. Como cada instituição mantém seu próprio banco de dados, o usuário busca geralmente as instituições de referência. As demais instituições, que ainda não têm visibilidade nacional, mas que estão em plena produção científica, não são muito acessadas, constituindo um círculo vicioso de não valorização do seu repositório institucional. Ele acaba sendo abandonado por falta de visibilidade.

$\mathrm{Na}$ tentativa de minimizar esses problemas, são criados portais coletores como o Oasisbr (oasisbr.ibict.br), o qual agregaria os metadados dos repositórios cadastrados e 
interoperáveis com o sistema de busca do portal. Entretanto, não têm se mostrado eficazes, visto que os documentos ficam armazenados no repositório da instituição de origem, gerando links quebrados por falta de manutenção do banco de dados. Ainda, repositórios já em funcionamento que não foram desenvolvidos segundo as especificações de interoperabilidade relutam em realizar as adaptações necessárias para integrar o portal.

Em 15 de fevereiro de 2006 a CAPES publicou a Portaria no 13 que institui a divulgação digital das teses e dissertações produzidas pelos programas de doutorado e mestrado reconhecidos. O documento esclarece que a produção científica discente é um importante indicador da qualidade dos programas de mestrado e doutorado e que assim, para fins de acompanhamento e avaliação periódica do reconhecimento dos cursos, os programas deveriam instalar e manter arquivos digitais acessíveis ao público por meio da internet. Com isso, foi documentada a obrigatoriedade de entrega de versão eletrônica pelo aluno concluinte.

Após a portaria da CAPES, a alimentação das bibliotecas digitais de teses e dissertações tem acontecido mediante inclusão nos regimentos dos programas de pós-graduação da obrigatoriedade de entrega do documento em sua versão eletrônica e assinatura de termo de direitos autorais, colocando-se como requisito para posterior solicitação de colação de grau. A título de exemplo, temos o texto do Regimento do Programa de Pós-graduação em Comunicação da Universidade Federal de Pernambuco, que em seu Capítulo VI- Da Conclusão dos Cursos- Artigo 40 informa:

Art. 40 - Havendo modificações de ordem formal indicadas pela Comissão examinadora, estas deverão ser realizadas no prazo de 30 (trinta) dias e entregues à Coordenação cinco cópias impressas em capa dura (no caso do Mestrado) ou oito cópias impressas em capa dura (no caso do Doutorado), uma cópia digitalizada da versão definitiva da dissertação ou tese e o comprovante da Biblioteca Central de depósito de uma cópia impressa (com as assinaturas dos examinadores) e uma cópia digitalizada da versão definitiva.

Parágrafo único - Somente após cumpridas tais indicações o/a estudante poderá requerer a Colação de Grau. (PPGCOM/UFPE)

Os bancos de dados científicos que têm alcançado maior adesão das instituições brasileiras são as bibliotecas digitais de teses e dissertações, mantidas pelas universidades e seus programas de pós-graduação, notadamente em instituições públicas de ensino. De modo a facilitar a busca por esses documentos, contamos com duas iniciativas: o IBICT desenvolveu a Biblioteca Digital Brasileira de Teses e Dissertações (BDTD), portal coletor que utiliza as tecnologias OAI, mas que depende do perfeito funcionamento dos bancos de dados locais para apresentação do documento completo; e a CAPES disponibiliza seu Banco de Teses 
(http://bancodeteses.capes.gov.br/), composto por informações enviadas pelas secretarias dos programas de pós-graduação. Em consultas realizadas em setembro de 2014, ambos os sistemas apresentavam falhas na apresentação dos resultados. A principal causa identificada foi a dificuldade de alimentação dos bancos de dados, que dependem diretamente dos programas de pós-graduação, com dados mantidos ou informados por estes.

Se os repositórios institucionais apresentam os problemas mencionados e podem assim serem comparados ao investimento dispersivo em carros, então como poderia ser o nosso "trem da comunicação científica"? Qual seria a solução coletiva, baseada na concentração de fluxos? Quem seria o responsável em planejar, implementar, manter e incentivar a participação da comunidade? Sugerimos como solução a criação de uma Plataforma de Conhecimento para a ciência brasileira, de responsabilidade MCTI, capaz de agregar todo o conhecimento científico produzido no Brasil. A responsabilidade pela implementação e manutenção técnica da plataforma seria, então, centralizada em uma única equipe subordinada ao MCTI, devolvendo às mãos do ministério o papel de investir alto numa solução coletiva, pois "já nos livramos da presunção do século XX - nunca universal, embora muito difundida - de que o Estado costuma ser a melhor solução para qualquer problema existente. Agora precisamos nos libertar da noção oposta: a de que o Estado é - sempre, e por definição - a pior opção disponível" (JUDT, 2011, p. 184).

\section{PLATAFORMA DE CONHECIMENTO PARA A CIÊNCIA BRASILEIRA}

A concepção de uma Plataforma de Conhecimento parte do reconhecimento do estágio atual de utilização das redes digitais, sobressaindo-se os ambientes de produção colaborativa, ou seja, a lógica da Web 2.0. Esse termo foi cunhado por TIM O'Reilly em 2003 quando afirmou que a Web 2.0 é "a mudança para uma Internet como plataforma, e um entendimento das regras para obter sucesso nesta nova plataforma", ressaltando como regra fundamental o aproveitamento da inteligência coletiva. A Web 2.0 se baseia no desenvolvimento de uma rede de informações onde cada usuário pode não somente usufruir, mas também contribuir. Assim, mais do que acesso, a Web 2.0 propicia produção, agora em ambientes online, com ferramentas gratuitas e abertas a todos os usuários, e não mais em softwares instalados localmente em cada computador. A título de conceituação, entendemos então que uma Plataforma é um ambiente online de produção de conteúdo e disponibilização em rede. 
Um exemplo brasileiro de plataforma utilizada pela comunidade científica é a Plataforma Lattes, mantida pelo Conselho Nacional de Desenvolvimento Científico e Tecnológico (CNPq). Em site oficial, a plataforma é assim apresentada (http://lattes.cnpq.br):

A Plataforma Lattes representa a experiência do CNPq na integração de bases de dados de Currículos, de Grupos de pesquisa e de Instituições em um único Sistema de Informações. [...] A disponibilização pública dos dados da Plataforma na internet dão maior transparência e mais confiabilidade às atividades de fomento do CNPq e das agências que a utilizam, fortalecem o intercâmbio entre pesquisadores e instituições e é fonte inesgotável de informações para estudos e pesquisas. Na medida em que suas informações são recorrentes e cumulativas, têm também o importante papel de preservar a memória da atividade de pesquisa no país.

Na Plataforma Lattes, cada pesquisador informa seu currículo, dentro dos parâmetros reconhecidos pelo CNPq, disponibilizando-o online para consultas. Além de gerar informações e estatísticas para o próprio Conselho, responsável pela gestão de recursos de financiamento para pesquisa, os dados são utilizados também pela comunidade científica como um todo, incluindo gestores de universidades e faculdades públicas e privadas, agências de fomento, centros de pesquisa. Enfim, no Brasil, um pesquisador somente é reconhecido em sua carreira se mantém atualizado seu currículo Lattes, referência para sua contratação ou financiamento. A comunidade científica brasileira já trabalha, portanto, com uma plataforma de dados curriculares reconhecida como referência mundial.

A Plataforma de Conhecimento que sugerimos estaria ligada diretamente ao currículo de cada pesquisador na Plataforma Lattes. Elas seriam, portanto, complementares. Toda publicação citada pelo pesquisador em seu currículo - seja artigo científico, capítulo de livro, livro, relatório científico (dissertações e teses) - poderá ser disponibilizada em acesso livre na Plataforma de Conhecimento. Sua validação curricular dependeria dessa disponibilização. Assim como é necessário comprovar a participação em eventos ou cursos apresentando certificados, as publicações seriam validadas com a inclusão de seu conteúdo na plataforma.

A centralização das informações num único banco de dados nacional não significaria apenas concentração dos investimentos federais, mas diversas vantagens para a comunidade acadêmica:

a. o currículo Lattes já confere a pesquisadores de todo o Brasil a possibilidade de serem "encontrados" numa busca no banco de dados da plataforma independente da instituição a que estão ligados. Buscas por assunto, ou área de conhecimento, trazem como resultado pesquisadores de grandes e pequenas instituições. A mesma oportunidade de visibilidade aconteceria na Plataforma de Conhecimento, pois os 
usuários não estariam pesquisando no repositório institucional apenas de universidades de grande visibilidade, mas num banco de dados nacional.

b. acessar um banco de dados único, com acesso livre a conteúdos completos, reduz o tempo dedicado pelos pesquisadores na busca de informações científicas. Hoje, nos vemos absorvidos por horas na rede, utilizando buscadores comerciais como o Google Acadêmico ou a iniciativa pública do Portal SciELO (Scientific Electronic Library Online). Vale diferenciar nossa Plataforma de Conhecimento de um portal como o SciELO. O modelo de publicação do SciELO prevê a inclusão de conteúdos científicos validados anteriormente por periódicos ou editoras aprovados pelo portal, o que representa um funil, não podendo representar toda a produção brasileira.

c. A Plataforma de Conhecimento poderá gerar dados bibliométricos de citação entre pesquisadores brasileiros.

d. O Governo brasileiro poderá disponibilizar os metadados de toda a plataforma para indexadores internacionais, conferindo de forma igualitária para todos os pesquisadores a possibilidade de visibilidade mundial.

Assim, com base nas vantagens de um pensamento Web 2.0, não estaríamos investindo tempo e dinheiro em hardwares e softwares localizados, mas numa estrutura computacional robusta, capaz de suportar toda a produção científica brasileira, sob a responsabilidade do $\mathrm{MCTI}$ de modo a garantir um banco de dados atual e disponível. Pois, como uma vez disse Keynes: "Não é suficiente que as condições que buscamos atingir sejam melhores do que as condições precedentes; elas devem ser melhores o bastante para compensar os males da transição" (apud JUDT, 2011, p. 144).

\section{PODEMOS AINDA MAIS}

Tratamos nesse artigo de defender a ideia da criação de uma Plataforma de Conhecimento para a ciência brasileira sob a responsabilidade do Ministério da Ciência, Tecnologia e Inovação, concentrando assim os esforços para acesso livre a informação científica produzida com financiamento público no Brasil.

Apresentamos argumentos capazes de demonstrar que os repositórios institucionais representam a dispersão - de investimentos, de esforços, de tempo - e que uma plataforma, a exemplo da já bem sucedida Plataforma Lattes de currículos - poderia concentrar os fluxos.

Mas podemos pensar ainda mais longe. Não precisamos assumir na Plataforma de Conhecimento o formato PDF, que torna a informação opaca para os sistemas de banco de 
dados. Com alimentação via formulários, a informação se torna transparente, possibilitando novas formas de filtros para acesso ao banco de dados. Podemos incluir possibilidades multimodais e mecanismos de incentivo a colaboração. Essas discussões estão sendo aprofundadas na tese de doutoramento da autora, a qual tem um caráter propositivo, com o objetivo de apresentar para o Governo brasileiro uma solução nos moldes aqui defendidos.

[...] o "individualismo" pode ser a tendência da nossa época, mas manifesta no que há de bom e de ruim, o isolamento conectado da era das comunicações. Contudo, o que distingue de fato a vida moderna não é o indivíduo desvinculado. É a sociedade (JUDT, 2011, p. 195).

\section{Referências}

ARELLANO, M.A.M.; FERREIRA, S.M.S.P; CAREGNATO, S.E. Editoração eletrônica de revistas científicas com suporte do protocolo OAI. In: FERREIRA, Sueli M. S. P.; TARGINO, Maria das Graças. Preparação de revistas científicas - teoria e prática. São Paulo: Reichmann \& Autores, 2005, pp. 195-229.

DARNTON, Robert. A questão dos livros: passado, presente e futuro. São Paulo: Companhia das Letras, 2010.

JUDT, Tony. 0 mal ronda a terra: um tratado sobre as insatisfações do presente. Rio de Janeiro: Objetiva, 2011.

LEITE, Fernando César Lima. Como gerenciar e ampliar a visibilidade da informação científica brasileira: repositórios institucionais de acesso aberto. Brasília: IBICT, 2009.

MASCARENHAS E SILVA, Fábio. SMIT, Johanna Wilhelmina. Sistemas nacionais de informação científica e tecnológica: um breve histórico. In SALCEDO, D. / OLIVEIRA, M. / OTERO, M. (org). Construção, práticas e identidades da Ciência da Informação. Recife: NECTAR, 2008, p. 57-78.

MEADOWS, Arthur Jack. J. A comunicação científica. Brasília: Briquet de Lemos/Livros, 1999.

Seer comemora adesão de 100 portais de periódicos. Disponível em:

$<$ http://www.ibict.br/sala-de-imprensa/noticias/seer-comemora-adesao-de-100-portais-deperiodicos>. Acesso em: 02 maio 2012.

Escolhendo uma licença. Disponível em:

$<$ http://www.creativecommons.org.br/index.php?option=com content\&task=view\&id=22\&lte mid=35>. Acesso em: 02 maio 2012.

Plataforma Lattes. Disponível em: $<$ https://wwws.cnpq.br/curriculoweb/>

Acesso em: 17 de maio 2012.

Standards for Web Content Interoperability. Disponível em:

<http://www.openarchives.org/>. Acesso em: 02 maio 2012. 